\title{
Defensive behavior and passive avoidance learning in rats and gerbils
}

\author{
MARY CRAWFORD \\ West Chester State College, West Chester, Pennsylvania 19380 \\ FRED A. MASTERSON \\ University of Delaware, Newark, Delaware 19711 \\ and \\ LOU ANN THOMAS and GREG ELLERBROCK \\ Buena Vista College, Storm Lake, Iowa 50588
}

\begin{abstract}
Rats and gerbils were found to differ in defensive behavior in three situations. In Experiment 1 , rats tended to crouch motionless in an open-field environment. Gerbils were more active and made more contact with objects. Experiment 2 compared the effect of noncontingent shock on the probability of five behaviors in the two species. Shock increased freezing in rats but had a less pronounced effect on freezing in gerbils. Experiment 3 showed superior passive avoidance performance in rats. The importance of testing the generality of theories of defensive behavior and avoidance learning through comparative research is discussed.
\end{abstract}

The formulation of general behavioral principles by extrapolation from the behavior of the laboratory rat has long been criticized (e.g., Beach, 1950; Lockard, 1968). In the area of aversive learning, such extrapolation has perhaps been fostered by a conceptual framework that views fear as a unitary drive construct, with fear offset providing reinforcement for any operant behavior the precedes it (Mowrer, 1947). According to this view, fear has similar effects on all species, and species differences in fear-related learning should be limited to those stemming from differences in operant repertoire.

In contrast, Bolles (1970) has proposed that fear imposes constraints on the response repertoire of rats. Bolles hypothesized that the frightened rat is limited to a small set of species-specific defense reactions (SSDRs) and that learning occurs in aversive situations through suppression of inappropriate SSDRs by punishment. Bolles' SSDR hypothesis provides a framework not only for studying the rat's behavior in fear-eliciting situations, but also for the gathering of comparative evidence on defensive reactions.

The experiments reported here provide comparative evidence on fear-related behavior in two rodent species, the rat and the gerbil (Meriones unguiculatus). In Experiment 1 , the animals were placed in a novel open-field environment, a situation that is assumed to engender conflict between mild fear and exploratory motivation

This research was supported by Grant MH28755 from the National Institute of Mental Health, a faculty development grant from Buena Vista College, and a research grant from West Chester State College, each to M. Crawford. The authors thank R. Chaffin, J. Esposito, and E. Pollak for their helpful comments on an earlier draft. Reprint requests may be sent to M. Crawford, Department of Psychology, West Chester State College, West Chester, Pennsylvania 19380.
(Montgomery, 1955). In Experiment 2, a more potent aversive stimulus, electric shock, was noncontingently presented in a novel environment, and its effects on several behaviors was assessed. Given the results of Experiments 1 and 2, it was predicted that rats and gerbils would differ in performance of a passive avoidance task; this prediction was tested in Experiment 3. Thus, the three experiments were designed to assess the occurrence of innate defense reactions under low to moderate levels of fear and to compare learning rates in an aversively motivated task.

\section{EXPERIMENT 1}

Experiment 1 compared the behavior of rats and gerbils in an open-field situation.

\section{Method}

Subjects. Subjects were 10 Sprague-Dawley rats obtained from Nebraska Scientific, Omaha, Nebraska, and 10 Mongolian gerbils (Meriones unguiculatus) obtained from the Huisman Company, Sheldon, Iowa. All subjects were naive, male, and at least 90 days old, and were maintained on ad lib food and water. They were housed individually and carried to the experimental room in their home cages.

Apparatus. The floor of a 1-m-square open-field apparatus was divided by black tape into $25-\mathrm{cm}$ squares. Its fiberboard walls were $28 \mathrm{~cm}$ high, and its top was open. Centered on the outside of one wall was a $23.5 \mathrm{~cm}$ long x $15 \mathrm{~cm}$ wide $\times 13 \mathrm{~cm}$ deep startbox made of wood painted flat black and connected to the apparatus by a manually operated guillotine door.

Objects placed in the apparatus on Trial 2 were a small glass jar with metal lid, a screwdriver, a wooden spool, and a plastic block.

Procedure. Each animal was given two 5-min trials in the open field. On Trial 1, a subject was placed in the startbox, and 10 sec later, the door was raised. Latency to leave the startbox was measured. If the animal had not left the startbox after $3 \mathrm{~min}$, the door was closed and the animal was picked up and placed in the center of the open field. Crossing was defined as 
moving all four feet across a line separating one square from another. After $5 \mathrm{~min}$, the animal was returned to the home cage for $1 \mathrm{~min}$, during which objects were distributed in the open field. The subject was then placed in the startbox; $10 \mathrm{sec}$ later the door was opened, and the animal's behavior was recorded, as on Trial 1. In addition, a third observer recorded behavior toward the objects. Object-directed behavior was defined as touching or manipulating the object with the head or front paws or sniffing with the nose $1 \mathrm{~cm}$ or less from the object. Each discrete incident of object-directed behavior was recorded. The apparatus was cleaned after each animal was run.

The rejection level for all analyses in Experiments 1-3 was set at $\mathrm{p}<.05$.

\section{Results and Discussion}

Interobserver correlations for Trial 1 were 1.00 and .95 for observations of rat and gerbil subjects, respectively. The corresponding correlations for Trial 2 were both 1.00 . When observers disagreed, the mean of their scores was used in all subsequent analyses.

Table 1 shows that the behavior of rat and gerbil subjects differed greatly. The gerbils' scores on every measure reflected greater activity. They rapidly left the startbox on both trials (longest observed latency was $6 \mathrm{sec}$ ). They explored the open field extensively. When objects were introduced to the field, they directed much exploratory behavior toward the objects. In contrast, every rat failed to leave the startbox within $3 \mathrm{~min}$ on both trials. Rats also made fewer crossings on both trials and engaged in less object-directed behavior. On each of the three measures, Mann-Whitney $U$ tests reflected the lack of overlap in distributions of scores for the two groups (in each case, $n_{1}=n_{2}=8, U=0$ ).

In informal observations, other differences in the behavior of the two species were noted. On both trials, rats tended to be thigmotaxic; most recorded crossings occurred when the rat moved along the sides of the enclosure. The rat's thigmotaxic tendencies, especially in novel or dangerous places, have been noted elsewhere (Barnett, 1975; Grossen \& Kelley, 1972). Such behavior was strikingly absent in the gerbils studied; their movement was much more evenly distributed over the entire area of the open field. Further, the observers noted qualitative differences in object-directed behavior. Gerbil subjects jumped onto the jar lid, rolled the spool, pushed the block, and, in general, engaged in much more

Table 1

Mean Activity Scores of Rats and Gerbils in Open Field

\begin{tabular}{|c|c|c|c|c|c|c|}
\hline \multirow[b]{2}{*}{ Group } & \multicolumn{2}{|c|}{$\begin{array}{c}\text { Latency to Leave } \\
\text { Startbox* }\end{array}$} & \multicolumn{2}{|c|}{$\begin{array}{l}\text { Number of } \\
\text { Crossings }\end{array}$} & \multicolumn{2}{|c|}{$\begin{array}{c}\text { Object-Directed } \\
\text { Behavior }\end{array}$} \\
\hline & Mean & SD & Mean & SD & Mean & SD \\
\hline & \multicolumn{6}{|c|}{ Trial 1} \\
\hline Rats & 180.0 & .00 & $\begin{array}{r}24.7 \\
\end{array}$ & 29.0 & & \\
\hline \multirow[t]{2}{*}{ Gerbils } & 34 & 1.17 & 163.8 & 16.4 & & \\
\hline & \multicolumn{6}{|c|}{ Trial 2} \\
\hline Rats & $\begin{array}{r}180.0 \\
3.2\end{array}$ & .00 & 12.8 & $\begin{array}{l}26.1 \\
10.5\end{array}$ & $\begin{array}{r}1.9 \\
26.0\end{array}$ & $\begin{array}{l}4.8 \\
1.3\end{array}$ \\
\hline
\end{tabular}

Note-Object-directed behavior was measured on Trial 2 only. *In seconds. protracted episodes and more direct contact with objects than did the rats, which tended to approach an object, sniff, and withdraw. The gerbils' object-directed behavior was probably related to territorial marking, which frequently occurs in open-field situations and is affected by the size and shape of objects in the environment (Thiessen, 1968). The scoring system used for object-directed behavior, which measured only discrete occurrences of such behavior, minimized qualitative and quantitative differences in the two species, and could be improved by the inclusion of measurements of duration and type of contact with objects.

The striking species differences observed in the openfield situation are consistent with other reports that gerbils are more active than rats in the running wheel (Powell \& Peck, 1969) and engage in more general activity and exploration in a maze (Thompson \& Lippman, 1972). While a novel open-field environment elicits a low activity level and much motionless crouching in the rat, it reveals no behavioral evidence of fear in the gerbil. It is possible that such environments are minimally or not at all aversive to the gerbil; thus a stronger aversive stimulus was used in Experiment 2.

\section{EXPERIMENT 2}

Experiment 2 investigated the behavior of rats and gerbils in a novel environment before and after presentation of noncontingent shock. Its purpose was to compare unlearned reaction to shock in the two species.

\section{Method}

Subjects. Subjects were five rats and five gerbils, the oddnumbered subjects from their respective groups in Experiment 1. At least $48 \mathrm{~h}$ intervened between the two experiments.

Apparatus. The apparatus was a $23 \mathrm{~cm}$ long $\mathrm{x} 20.5 \mathrm{~cm}$ wide $x 19.5 \mathrm{~cm}$ deep operant conditioning chamber. Two walls and the lid were of clear Plexiglas, and the remaining walls were metal. The floor of the chamber consisted of $.5-\mathrm{cm}$ stainless steel shock grids spaced $1.4 \mathrm{~cm}$ center to center. Scrambled electric shock was provided by a Grason-Stadler Model 700 ac constantcurrent (source voltage: $350 \mathrm{~V}$ ) shock generator.

Procedure. An animal was placed in the apparatus, and, $10 \mathrm{sec}$ later, two observers began recording its behavior at $10-\mathrm{sec}$ intervals, using the method of instantaneous event sampling (Altmann, 1974). An auditory cue (the click of a relay closure) signaled the observers to record the animal's behavior at the instant the click occurred. Pilot work had indicated that seven highly probable behaviors were easily distinguishable by observers and together accounted for nearly all activity in the apparatus. These behaviors were: crouch against wall, crouch (other than against wall), sniff, groom, rear, walk/run, and climb/jump. If the animal was walking, crouching, or rearing and also had its nose within $1 \mathrm{~cm}$ of a surface with vibrissa movement, the behavior was recorded as a sniff. Otherwise, the behaviors were mutually exclusive, although not intended to be exhaustive.

Observation and recording of the seven selected behaviors continued at $10-\mathrm{sec}$ intervals for $5 \mathrm{~min}$. At the end of the observation period, each animal received three noncontingent shocks separated by $5 \mathrm{sec}$ intervals. Each shock was $1 \mathrm{~mA}$ in intensity and $2 \mathrm{sec}$ in duration. Ten seconds after delivery of the third shock, the observers again began to record instances of the seven selected behaviors at 10 -sec intervals, continuing for $5 \mathrm{~min}$ as in the previous observation period. 


\section{Results and Discussion}

The observers recorded no instances of behaviors in the crouch-against-wall and climb/jump categories. Interobserver agreement on occurrences of the other categories was .99 for crouch, sniff, groom, and rear and .95 for walk/run.

The analysis of crouching showed a species difference $[\mathrm{F}(1,8)=132.82]$, an effect for trials $[\mathrm{F}(1,8)=185.18]$, and a Species by Trial interaction $[F(1,8)=58.07]$. Rats showed more initial crouching in the novel environment. As can be seen in Figure 1, presentation of noncontingent shock increased the occurrence of crouching in both species; however, the effect was much greater in rats.

The analysis of sniffing showed no effect for species $[F(1,8)=.64]$, but a large effect for trials $[F(1,8)=$ 165.55] and a Species by Trial interaction $[\mathrm{F}(1,8)=$ 20.99]. Sniffing was the predominant activity for rats before shock but dropped to nearly zero after shock. Sniffing behavior decreased less in gerbils.

Analyses of the other three behavior categories also showed significant effects. Grooming behavior was infrequent for both species, but while it dropped out in rats after shock, it increased slightly in gerbils. The ANOVA showed a species difference $[F(1,8)=13.61]$ and a Species by Trial interaction $[F(1,8)=5.34]$, but no effect for trials $[F(1,8)=.09]$. Rearing behavior was more frequent in gerbils and increased following shock. Here, the ANOVA revealed a species effect $[F(1,8)=$ $25.22]$, a marginally significant trials effect $[F(1,8)=$ $5.30]$, and a Species by Trial interaction $[F(1,8)=8.05]$. Gerbils were initially more likely than rats to walk/run, but they decreased their level of this activity after shock more than rats did. The walk/run analysis showed effects for species $[F(1,8)=22.17]$, trials $[F(1,8)=11.13]$, and the interaction $[\mathrm{F}(1,8)=10.07]$.

In summary, the analyses showed that noncontingent shock affects the two species differently on every behavior category measured. These differences are not due to species differences in reactivity to shock. Rats and gerbils do not differ, for example, in performance of

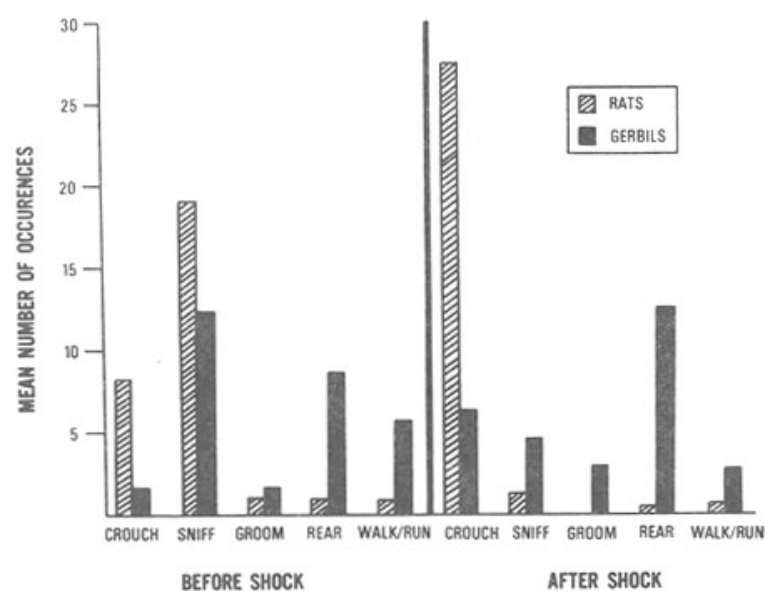

Figure 1. Occurrence of selected behaviors in rats and gerbils before and after presentation of noncontingent shock. a one-way avoidance task when given shock of equal intensity (Ashe \& McCain, 1972). In the present situation, however, the effect of brief, moderate-intensity, noncontingent shock in rats is to reduce all behaviors except crouching to nearly zero, including the most frequent preshock activity of sniffing. When escape is not possible, the frightened rat limits its repertoire to a single behavior, that of motionless crouching. The effect of shock on gerbils is less pronounced. The typical gerbil becomes less likely to sniff and more likely to rear, a behavior that may be the "alert-posturing" response previously hypothesized to be a defense behavior in gerbils (Walters \& Glazer, 1971). However, it continues to emit all the recorded behaviors after shock. Thus the effect of shock in limiting the behavioral repertoire is much greater for rats than for gerbils.

\section{EXPERIMENT 3}

Experiment 3 compared the performances of rats and gerbils in an aversive conditioning situation that requires the inhibition of responding, the passive avoidance paradigm. It was predicted that fear-induced freezing behavior in the rat would facilitate its performance on this task compared with that of the gerbil, which remains active following shock.

\section{Method}

Subjects. Subjects were 15 rats and 16 gerbils similar to those in Experiment 1.

Apparatus. Training and testing were conducted in a commercial ledge-jump apparatus in which an 11.43 by $19.69 \mathrm{~cm}$ portion of one wall retracts, revealing an $11.43 \mathrm{~cm}$ high by $19.69 \mathrm{~cm}$ wide by $12.70 \mathrm{~cm}$ deep ledge $8.26 \mathrm{~cm}$ above the chamber floor. The chamber size with ledge closed was 22.86 by 21.59 by $20.96 \mathrm{~cm}$. Its floor consisted of .48 -cm-diam stainless steel grids placed $1.59 \mathrm{~cm}$ apart center to center.

The shock source was the same as in Experiment 2. Response latencies were recorded by an electronic clock (10-Hz output) and a printout counter.

Procedure. For rats and gerbils in the passive avoidance groups (PAR and PAG, $n=8$ each), training began with the animal's placement on the ledge of the apparatus. When the animal stepped down to the grid floor, it received a shock of $1 \mathrm{~mA}$ intensity and $3 \mathrm{sec}$ duration. Five seconds after shock offset, the subject was removed to its home cage for a 30-sec intertrial interval (ITI). At the end of the ITI, the animal was replaced on the ledge for the beginning of the next trial. Beginning with its first step-down response, each subject was run for seven trials, with the response-shock contingency in effect for every trial. Failure to step down from the ledge within $60 \mathrm{sec}$ on any trial led to termination of that trial and removal to the home cage for the ITI. In addition, a group of nonshocked rats (Group NR, $n=7$ ) and one of gerbils (NG, $n=8$ ) received handling identical to that of the experimental groups, except that shock was never presented.

\section{Results and Discussion}

Mean latencies for the first step-down trial were similar for the four groups (PAR, $21.62 \mathrm{sec}$; PAG, $26.59 \mathrm{sec}$; NR, $22.14 \mathrm{sec}$; and NG, $23.37 \mathrm{sec}$ ) and did not differ reliably $[F(3,27)=.11]$.

Rats and gerbils differed in their learning of the passive avoidance task. The effect of a single CS-US 


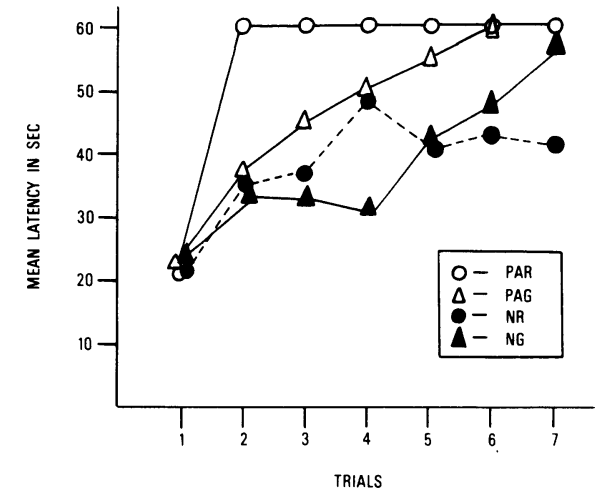

Figure 2. Passive avoidance performance in rats (PAR), gerbils (PAG), and nonshocked control groups (NR and NG).

pairing on behavior on the following trial can be seen in a comparison of the mean latencies for the four groups on the first trial following shock. Latencies for Group PAG were very similar to those for the unshocked control groups (PAG, $37.83 \mathrm{sec}$; NR, $35.57 \mathrm{sec}$; NG, $35.75 \mathrm{sec})$. In contrast, every rat in Group PAR had a latency of $60 \mathrm{sec}$. This single-trial effect was marginally significant [Kruskal-Wallis $\mathrm{H}(3)=6.94, \mathrm{p}<.10$ ] . Thus a single response-shock pairing was sufficient to completely inhibit step-down responding on the following trial for rats, whereas gerbils' responding was indistinguishable from that of nonshocked rats and gerbils.

The two species' tendency to differ increased over subsequent trials. In comparison with the immediate response inhibition of rats, the mean number of trials required by gerbils to reach a criterion of one $60-\mathrm{sec}$ trial without responding was 2.5 , a significant difference $\left(\mathrm{n}_{1}=\mathrm{n}_{2}=8\right.$, Mann-Whitney $\left.\mathrm{U}=56\right)$. An analysis of response latencies over all seven trials showed no overall effect for groups $[\mathrm{F}(3,26)=2.21]$, but a large effect for trials $[F(6,156)=19.78]$ and a significant Groups by Trials interaction $[F(18,156)=1.66]$. As shown in Figure 2, the pattern established on the first test trial was maintained: Rats sustained their complete inhibition of step-down responding, whereas gerbils showed a gradual increase in step-down latency similar to that of unshocked rats and gerbils. The procedures used here cannot, of course, assess whether rat subjects learned the response-shock contingency or simply performed a freezing defense reaction following shock. It is clear, however, that gerbils were slower to inhibit responding than rats, a difference predicted by their performances in Experiments 1 and 2.

\section{GENERAL DISCUSSION}

The present experiments show differences between rats and gerbils in all three situations investigated: open-field behavior, unlearned reactions to noncontingent shock, and passive avoidance performance. For both species, fear appears to have a direct effect of constraining the response repertoire as predicted by Bolles' (1970) SSDR hypothesis. Such fear-induced response constraints are more pronounced in rats than in gerbils (Experiments 1 and 2).
The present pattern of results also indicates species differences in the responses primed or elicited by fear. These results are consistent with evidence that gerbils perform much better than rats in the more active tasks of shuttle avoidance (Ashe \& McCain, 1972) and barpress avoidance learning (Powell \& Peck, 1969; Walters, Pearl, \& Rogers, 1963). Gerbils' performance is better than that of rats partly because fear arousal primes a group of behaviors that is compatible with the demands of these laboratory tasks. For example, rearing, which increases in gerbils following shock, and sniffing, which remains probable, may facilitate barpressing. In contrast, the rat freezes, at least in the environments studied here, to the near exclusion of all other responses. Comparisons of related species in a variety of laboratory tasks would be useful in further delineating the interaction of innate defensive reactions and the requirements of avoidance learning tasks.

Dewsbury (1974) has pointed out that the rodent superfamily Muroidea, to which the Norway rat and the Mongolian gerbil both belong, has many advantages for comparative study. The group is ecologically and behaviorally varied. It includes many species that are easily obtained, docile, and adaptable to the laboratory animal colony and equipment designed for rats. Although research on the defensive behavior of most muroid species has been scant, these animals may provide a practical and appropriate avenue for testing the generality of theories of aversive learning.

\section{REFERENCES}

Altmann, J. Observational study of behavior: Sampling methods. Behaviour, 1974, 49, 227-267.

Ashe, V. M., \& McCAin, G. Comparison of one-way and shuttleavoidance performance of gerbils and rats. Journal of Physiological Psychology, 1972, 80, 293-296.

BARnetr, S. A. The rat: A study in behavior. Chicago: University of Chicago Press, 1975.

Beach, F. A. The snark was a boojum. American Psychologist, 1950, 5, 115-124.

Bolles, R. C. Species-specific defense reactions and avoidance learning. Psychological Review, 1970, 71, 32-48.

Dewsbury, D. Methods and designs: The use of muroid rodents in the psychology laboratory. Behavior Research Methods \& Instrumentation, 1974, 6, 301-308.

Grossen, N. E., \& KeLLey, M. J. Species-specific behavior and acquisition of avoidance behavior in rats. Journal of Comparative and Physiological Psychology, 1972, 81, 307-310.

LOCKARD, R. B. The albino rat: A defensible choice or a bad habit? American Psychologist, 1968, 23, 734-742.

Montgomery, K. C. The relation between fear induced by novel stimulation and exploratory beahvior. Journal of Comparative and Physiological Psychology, 1955, 48, 254-260.

Mowrer, O. $\mathbf{H}$. On the dual nature of learning: A reinterpretation of "conditioning" and "problem-solving." Harvard Educational Review, 1947, 17, 102-148.

Powell, R. W., \& PECK, S. Running-wheel activity and avoidance in the Mongolian gerbil. Journal of the Experimental Analysis of Behavior, 1969, 12, 779-787.

Thiessen, D. D. The roots of territorial marking in the Mongolian gerbil: A problem of species-common topography. Behavior Research Methods \& Instrumentation, 1968, 1, 70-76.

Thompson, R. W., \& Lippman, G. Exploration and activity in the gerbil and rat. Journal of Comparative and Physiological Psychology, 1972, 80, 439-448.

Walters, G. C., \& Glazer, R. D. Punishment of instinctive behavior in the Mongolian gerbil. Journal of Comparative and Physiological Psychology, 1971, 75, 331-340.

Walters, G., Pearl, J., \& Rogers, J. The gerbil as a subject in behavioral research. Psychological Reports, 1963, 12, 315-318.

(Received for publication June 29, 1981.) 